\title{
A descriptive, historical, and thematic analysis of Acta Dermatovenerologica Alpina, Pannonica et Adriatica
}

\author{
Jovan Miljkovic ${ }^{1,2}$, Mario Poljak ${ }^{3,4}$, Anja Šterbenc ${ }^{3,5}$, Peter Kokol ${ }^{6 凶}$
}

\begin{abstract}
Introduction: Journal bibliometric indicators are useful tools in assessing the characteristics, development history, and future trending of a particular medical journal. Moreover, they can help potential authors when deciding which journal to submit their work to in order to achieve the highest visibility.

Methods: A single journal study of the medical journal Acta Dermatovenerologica Alpina, Pannonica et Adriatica (ADAPA) from January 1994 to July 2019 was performed. The corpus was harvested from the bibliographical database Scopus (Elsevier, Netherlands) for the period between 1994 and 2019 (inclusive), and the bibliometric analysis was performed using Scopus built-in services and MS Excel (Microsoft, USA). The historical, cooperation, and hot topic analysis was performed on scientific landscapes induced by VOSviewer software (Leiden University, Netherlands).

Results: From 1994 to 2019, a total of 759 publications were published in ADAPA. The trend in the number of publications has varied; it increased somewhat until 2009, then decreased until 2015, when the number of articles began to rise again, reaching a peak in 2018 (46 articles annually). A small decline in source normalized impact per paper (SNIP) was observed from 1.2 in 2010 to 0.46 in 2018. Slovenia ranked first $(n=210)$ in the number of publications among 55 countries. Authors from 44 out of 55 countries published their articles through co-authorships.

Conclusions: Whereas it was initially considered a primarily regional journal, ADAPA's influence has gradually broadened and the journal has become truly international. The number of articles published increased significantly during the last few years, with ADAPA strongly supporting international collaboration, resulting in a high proportion of international co-authorships.
\end{abstract}

Keywords: dermatology, single journal study, bibliometrics, bibliometric mapping, scientific landscapes

Received: 8 August 2019| Returned for modification: 23 October 2019| Accepted: 3 November 2019

\section{Introduction}

Single journal studies have a long history in bibliometric research. In general, they deal with bibliometric, citation, and content analyses, as well as with other bibliometric aspects of a single journal in order to present the journal's characteristics and inform potential authors. Single journal studies have mostly been devoted to sciences and technology, and medical sciences, followed by library and information science, arts, humanities, and social sciences (1). The journals analyzed have been indexed by major databases, such as Web of Science, Scopus, or PubMed.

Studies on single journals present various types of bibliometric measures, including the productivity of authors and their affiliations; authors' sex, profession, and rank; degree of collaboration among authors; affiliations and countries; keyword analysis; keyword co-occurrences; impact factor (IF) (2); thematic analysis (3); "sleeping beauties" (4); and characteristics of editorial boards (5). Some recent examples of single journal studies were performed for Computers in Human Behavior (6), Journal of Advanced Nursing (3), Forests (7), Remote Sensing (8), and Tissue Engineering (9). Interestingly, recent single journal studies have been extended to include multiple journal studies; namely, nursing journals (10), medical informatics journals (11), and sports science journals (12).

The publication of the first issue of Acta Dermatovenerologica Alpina, Pannonica et Adriatica (ADAPA) in 1992 was the vision- ary outcome of one of the leading researchers in the history of dermatology in central Europe, Aleksej Kansky. His vision was to establish a journal that would serve as a forum for research and discussion, sharing the ideas and experience of professionals in the region and beyond. He was also the first editor-in-chief until 2009, when he stepped down and became editor emeritus. He was followed by Jovan Miljković, who is currently serving as acting editor-in-chief, assisted by Mario Poljak, Aleksandar Godić, and Boštjan Luzar as editors. Since 2005, the journal has been indexed in Index Medicus/MEDLINE, EMBASE/Excerpta Medica, and Biomedicina Slovenica, and it started being covered by Emerging Sources Citation Index (ESCI), the Thomson Reuters Web of Science Core Collection index, in 2016 (13).

Despite the fact that ADAPA is a "small journal from a small country," it is believed that it has significantly improved its quality and international profile since 1992 and fulfilled and possibly exceeded the vision and expectations of its founding father, Aleksej Kansky. ADAPA history and its achievements have been presented and briefly analyzed previously (13-15); however, no full single journal analysis has been performed to date. Hence, in this study we performed an extensive bibliometric analysis of ADAPA publishing history, covered by SCOPUS (Elsevier, Netherlands), focusing on descriptive bibliometric measures, evolution of topics, co-authorship cooperation, and identification of hot topics. 


\section{Methods}

The search was conducted on July 21st, 2019 in the bibliographical database Scopus, using the search string Acta Dermatovenerologica Alpina, Pannonica et Adriatica in the Source title field, for the period from January 1st, 1994 to July 19th, 2019. To perform the descriptive bibliometric analysis (including distribution of types of documents) and identify the most prolific organizations and countries publishing in ADAPA, we used the Scopus built-in analysis services. For the trends analyses of ADAPA publication characteristics (number of publications, average number of pages, references, authors, organizations, and citations per publication), we exported the publication metadata to Excel (Microsoft, USA) and calculated the averages with the Excel built-in text and statistical functions.

To analyze the historical and thematic context of ADAPA literature production, we induced various scientific landscapes, as well as coauthors and keyword co-occurrence networks, using VOSviewer software V1.6.11 (Leiden University, Netherlands). We analyzed publication titles and abstracts; however, we omitted general/common terms, such as study, significance, method, baseline, and time stamps. To analyze the evolution of terms, we used the author-keyword timeline landscape. We assessed country cooperation by using the country co-authorship network. To identify hot topics, we used the approach recently proposed by Kokol et al. (16).

\section{Results and discussion}

\section{General information}

From 1994 to 2019, a total of 759 publications were published in ADAPA. Among them there were 557 (73.4\%) research articles, $100(13.2 \%)$ review articles, 54 (7.1\%) conference papers, $19(2.5 \%)$ letters to the editor, $14(1.8 \%)$ editorials, eight $(1.1 \%)$ retractions and errata, and seven (1.0\%) short reports.

Despite the fact that ADAPA started being published in 1992, Scopus only covers it from 1994 (Volume 3) onward. As shown in Figure 1, the trend in the number of publications has not been steady; it somewhat increased until 2009, and then decreased until 2015, when it reached the lowest annual number of published articles. Following intense efforts to increase the visibility of ADAPA and announcement of free-of-charge publication for all article types in 2017 in order to promote original clinical and scientific research that would not be submitted otherwise because of authors' financial restrictions, the number of published articles began to rise again, reaching a peak in 2018, with 46 articles per year. However, because of a large increase in the number of case reports and letters to the editor submitted to ADAPA in 2018, the editors

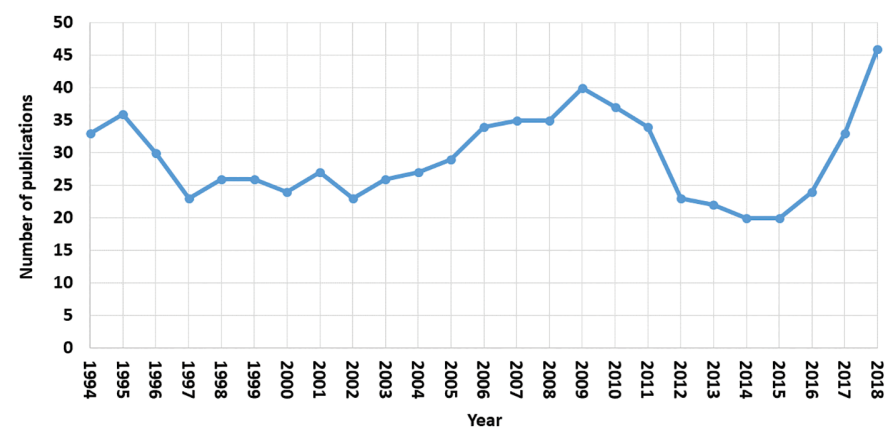

Figure 1 | The dynamics of ADAPA literature production 1994-2018. decided to reinstate article processing charges for case reports and letters to the editor in January 2018 in order to ensure timely publication of the most influential research. Interestingly, it seems that this measure did not deter authors from submitting to ADAPA because 26 contributions were published in the first half of 2019, indicating that the positive trend will most probably continue.

\section{The dynamics of source normalized impact per paper trend}

Scopus started to calculate ADAPA's source normalized impact per paper (SNIP) in 2002. The SNIP is calculated as the ratio of the journal's average citation count per publication to the average number of references in reference lists of citing articles, and it may be a more appropriate tool for assessing a journal's influence than an official IF. This is due to two reasons: i) the SNIP evaluates contextual citation impact, accounting for the citation potential of the respective field, and ii) on some occasions, SNIP values can predate IF or are the only metric to assess journals that have not yet been granted an official IF (as in the case of ADAPA) (17). For ADAPA, the SNIP rapidly increased from less than 0.2 to almost 1.2 in 2010, and then started to decrease to 0.46 in 2018 (Fig. 2). The previous ADAPA citation analyses performed in 2012 and 2015 (18, 19) showed positive dynamics of the predicted IF with the highest values (>1.0) achieved in 2013. However, SNIP values have been relatively stable since then, suggesting that the future of ADAPA is encouraging. Whereas important modifications in editorial policy were applied only recently, it might still be too early to notice the full impact of these interventions (e.g., discontinuation of publishing fees for original articles and reviews). The editors of ADAPA sincerely hope that Thomson Scientific will soon recognize our efforts and award ADAPA an official IF $(15,19)$.

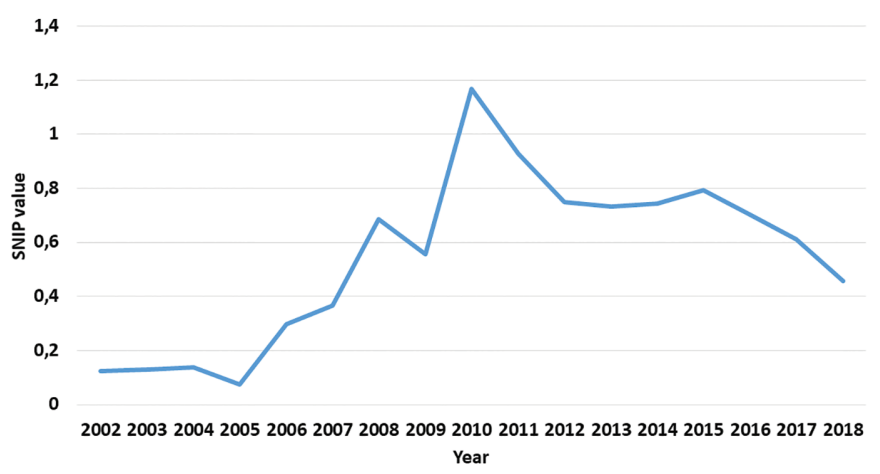

Figure 2 | The dynamics of source normalized impact per paper (SNIP).

\section{Geographical distribution of ADAPA publications}

The publications originated from 55 different countries, mostly from Slovenia $(n=210)$, Italy $(n=88)$, Turkey $(n=48)$, Austria $(n=46)$, and Germany $(n=34)$. Out of 177 institutions, the Ljubljana University Medical Center, Slovenia $(n=106)$ was the most productive, followed by the University of Ljubljana, Slovenia $(n=$ 74), University of Trieste, Italy $(n=29)$, Rutgers New Jersey Medical School, United States ( $n=27)$, Karl Franzens University, Graz, Austria $(n=21)$, and University of Maribor, Slovenia $(n=16)$ and Maribor University Medical Center, Slovenia $(n=16)$. Surprisingly, only six publications had officially declared funding sources. The most prolific among the four funding agencies was the Slovenian Research Agency, with three funded publications.

Our results further confirm the regional importance of ADAPA (15) and show that the journal is an attractive platform for promot- 
ing science among Slovenian researchers and clinicians. The visibility of ADAPA is increasing, and authors from various countries are submitting their work to ADAPA. Since 2017, we have noticed an increase in publications originating from the Middle East and India (data not shown), which is probably a direct result of dropping article processing charges because publishing in standard open-access journals (with relatively high open-access fees) may not be financially feasible for researchers with limited funds.

\section{Bibliometric characteristics of CSN publications}

Figure 3 shows trends in bibliometric characteristics for ADAPA. The average number of authors and institutions per published article is increasing, contrary to the average number of pages per article, which is slightly decreasing. It appears that in recent years collaboration between authors and institutions is becoming increasingly popular and is most likely a result of the "globalization" of science and the surge in available centers providing observerships to researchers from abroad. The average number of citations per article curve is typically bell shaped, with the peak values in the period between 2005 and 2008, reaching around 15 citations per publication.

The number of references varied largely between years, with no clear trend (Fig. 3). Review articles (dotted line in Fig. 3; their number is shown on the secondary axis on the right) tend to include more references than other types of articles and, because ADAPA does not have a fixed number of review articles published per issue, this may be reflected in the observed curve with no clear trends.

\section{Topic evolution}

The analysis of chronological evolution of topics was based on the timeline landscape of author keywords occurring at least five times (Fig. 4). Using this approach, a total of 44 author keywords

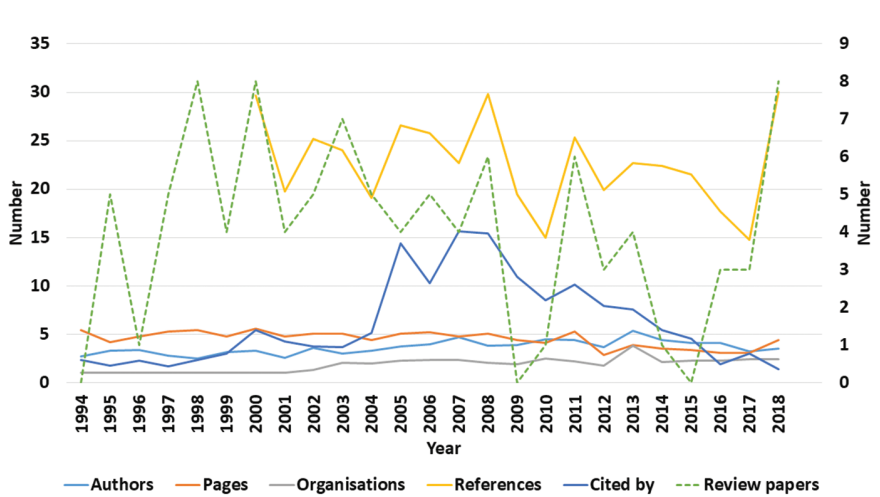

Figure 3 | The yearly averages trends of ADAPA descriptive bibliometric indicators.

emerged on the landscape. As shown in Figure 4, the topic evolution proceeded through four periods. In the first period, from 1994 to 2000 (violet), research focused on AIDS, Chlamydia trachomatis, and Lyme borreliosis and erythema migrans and their diagnosis. Anti-mycotic therapy (including itraconazole and terbinafine) in children also appeared to be popular topics during this period. The research in the second period, from 2001 to 2005 (blue), focused on skin, syphilis, sexually transmitted diseases, PCR, treatment, genetics, and epidemiology. The third period, from 2006 to 2009 (green), focused on HIV, psoriasis, mycosis fungoides, vitiligo alopecia, and lichen planus. After 2009, the research focus shifted to HPV, dermoscopy, squamous cell carcinoma, and hidradenitis suppurativa.

Interestingly, with chronological and technological advancement, the repertoire of highlighted topics appears to decrease. This could be due to use of more popular and/or broad-spectrum keywords or a shift in the research community's attention with respect to dermatological research.

The analysis may be somewhat hindered by the use of interchangeable terms, creating two separate results for the same term. For example, on some occasions the authors list human papillomavirus as a keyword whereas others use HPV. Moreover,

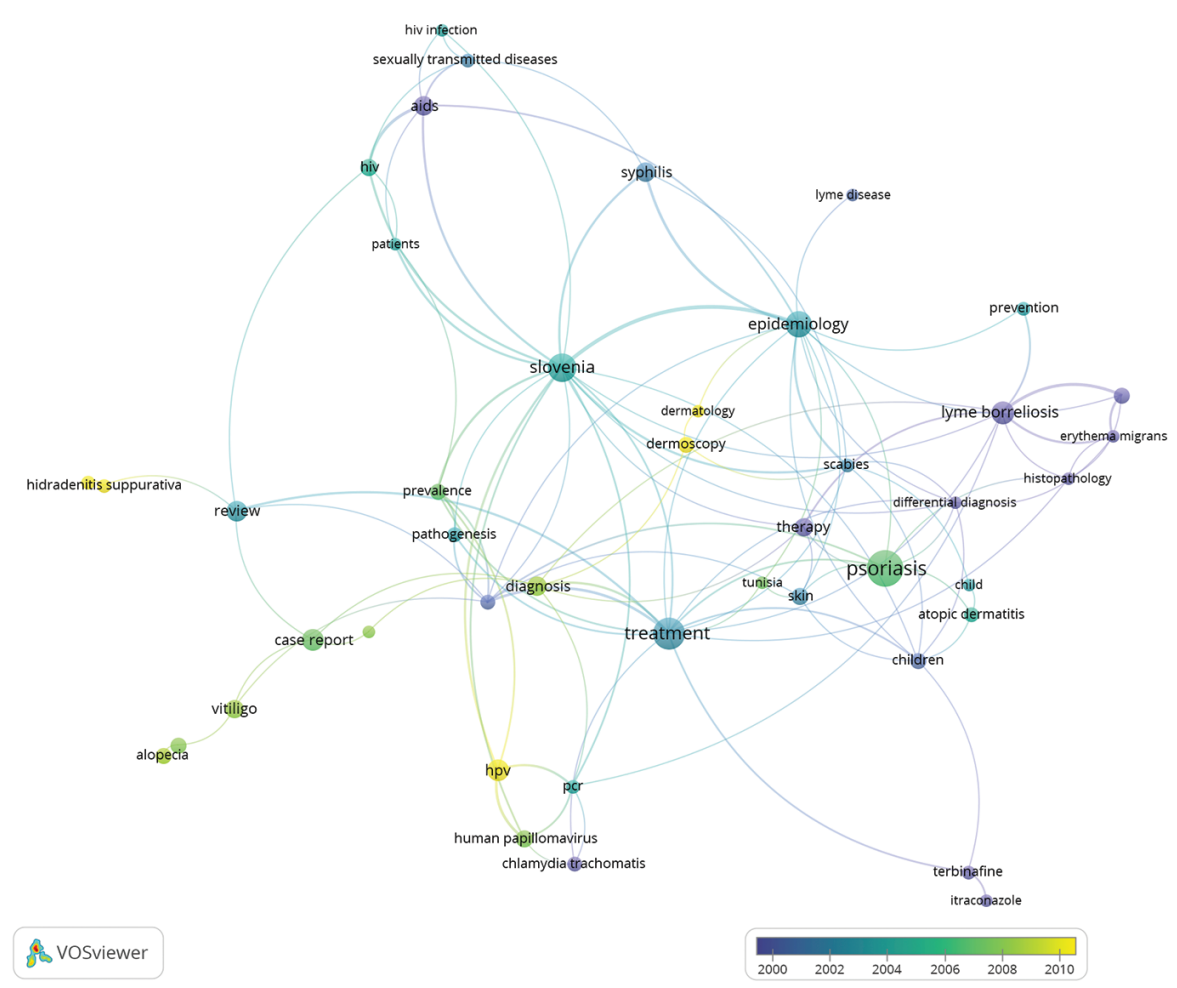

Figure 4 | The evolution of topics. Time periods are denoted using different colors. Violet represents the first period (1994-2000), blue the second (2001-2005), green the third (2006-2009), and yellow the last (after 2010). 
keywords with a comparatively low frequency that did not reach the threshold for analysis presentation might still be of clinical or scientific importance.

\section{Hot topics}

The hot topic analysis revealed five hot topics, including Koebner phenomenon, psychodermatology, psoriasis, adalimumab, and hidradenitis suppurativa. A hot topic is defined as a theme or a term that commonly appears over a period of time. Two variables influence the "hotness" of a topic; namely, how often the term is used in the literature and how many articles contain the relevant term (20). However, one must be aware that hot topics are not permanent: they evolve and are almost inevitably replaced by other, more up-to-date themes. With soaring amounts of available journals and published research articles, it might prove to be impractical and too time-consuming as well as strenuous to recover pertinent data on what topic is currently considered "hot." Nevertheless, based on our results, it appears that Koebner phenomenon, psychodermatology, psoriasis, adalimumab, and hidradenitis suppurativa are currently considered "hot" and might also be interesting topics for future research.

\section{Cooperation based on co-authorship}

Cooperation based on co-authorship is shown in Figure 5. The size of the circle represents the number of documents per country, with larger circles representing higher numbers of documents per country, and the color corresponds to the average number of citations per article, with yellow denoting the most-cited articles. Based on 759 publications analyzed, authors from 44 out of 55 countries cooperated through co-authorships, suggesting that international cooperation is common. International cooperation was most frequently observed for authors from Slovenia, who collaborated with authors from 30 other countries, followed by authors from Serbia and Poland (26 countries), the United States (21 countries), and Italy (18 countries). The strongest cooperation emerged between Slovenia and the United States, and between Slovenia and Serbia. Collaboration with other researchers can be a strategic solution for improving research performance because journal publications as well as article citations may constitute key criteria for obtaining research grants, teaching positions, and promotions (21).

The most cited publications were published by authors from the United Kingdom, Bosnia and Herzegovina, and Egypt. Interestingly, it seems that cooperation is not automatically correlated with a greater research impact because some of the articles with the highest citation figures (Fig. 5) did not result from international cooperation, as shown previously (21), although our findings may not be applicable to other medical fields and/or journals.

The most productive country was found to be Slovenia, with publications from Slovenian authors being cited on average six times. Our study showed that, although Slovenia is a relatively small European country, relevant and internationally recognized high-quality articles are produced by Slovenian researchers that regularly publish in ADAPA.

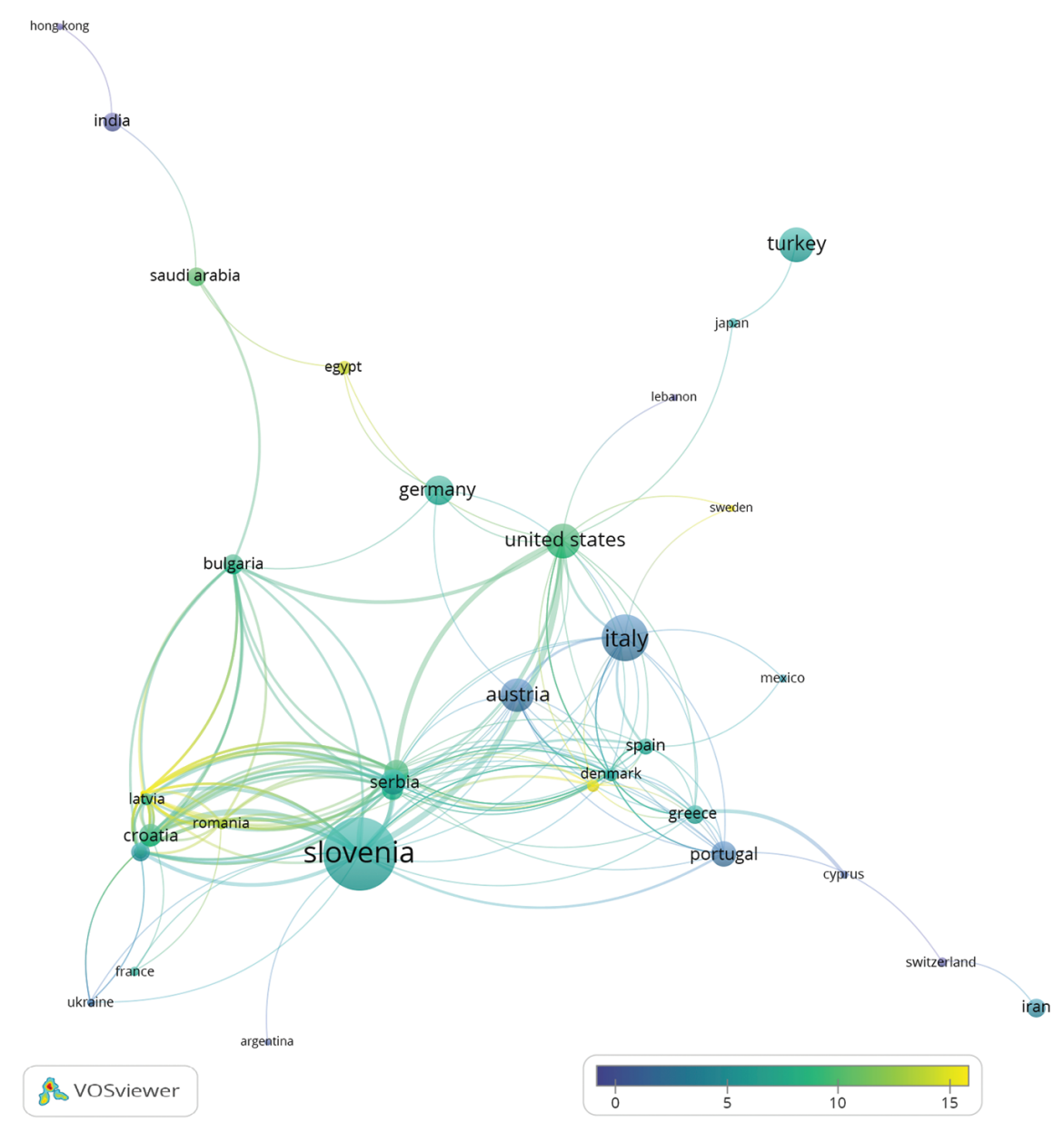

Figure 5 | Cooperation based on co-authorship between countries. The size of the circle represents the number of documents per country and the color corresponds to the average number of citations per article. 


\section{Conclusions}

Our study showed that the visionary aim of ADAPA's founders has not only been achieved, but admirably exceeded. Whereas initially considered to be of mostly regional importance, ADAPA's influence has gradually broadened and the journal has become truly international. Specifically, the authors that published in ADAPA

\section{References}

1. Zainab AN, Anyi KWU, Anuar NB. A single journal study: Malaysian Journal of Computer Science. Malaysian J Comput Sci. 2009;22:1-18.

2. Nageswara Rao K, Sharma RK, Girija Devi S, Muralidhar S. Bibliometric analysis of the Journal of Propulsion and Power (1985-2013). Desidoc J Library Info Technol. 2014;34:271-6.

3. Železnik D, Blažun Vošner H, Kokol P. A bibliometric analysis of the Journal of Advanced Nursing, 1976-2015. J Adv Nurs. 2017;73:2407-19.

4. Kokol P, Blažun Vošner H, Železnik D. Clinical Simulation in Nursing: a bibliometric analysis after its tenth anniversary. Clin Simul Nurs. 2017;13:161-7.

5. Okagbue HI, Atayero AA, Adamu MO, Oguntunde PE, Opanuga AA, Adamu PI. Analysis of dataset on editorial board composition of Dove Medical Press by continent. Data Brief. 2018;20:1440-5.

6. Vošner HB, Kokol P, Bobek S, Železnik D, Završnik J. A bibliometric retrospec tive of the journal Computers in Human Behavior (1991-2015). Comput Human Behav. 2016;65:46-58.

7. Uribe-Toril J, Ruiz-Real JL, Haba-Osca J, Valenciano JP. Forests' first decade: a bibliometric analysis overview. Forests. 2019;10:72.

8. Zhang Y, Thenkabail PS, Wang P. A bibliometric profile of the Remote Sensing open access journal published by MDPI between 2009 and 2018. Remote Sens. 2019;11:91.

9. Santisteban-Espejo A, Campos F, Martin-Piedra L, Durand-Herrera D, Moral-Munoz JA, Campos A, et al. Global tissue engineering trends: a scientometric and evolutive study. Tissue Eng Part A. 2018;24:1504-17.

10. Giménez-Espert MDC, Prado-Gascó VJ. Bibliometric analysis of six nursing journals from the Web of Science, 2012-2017. J Adv Nurs. 2019;75:543-54.

11. Blažun Vošner H, Železnik D, Kokol P. Bibliometric analysis of the International Medical Informatics Association official journals. Inform Health Soc Care. 2018; 23:1-17. are affiliated with 55 countries from all inhabited continents, with the exception of Australasia. ADAPA is indexed by all major indexing services, and the number of publications has steadily increased during recent years. Last but not least, in addition to being a forum for presenting influential research, ADAPA also supports international collaboration, resulting in a high proportion of international co-authorships.

12. Coimbra DR, Dominski FH, Correia CK, Andrade A. Scientific production in sports science journals: bibliometric analysis. Rev Bras Med. 2019;25: 88-93.

13. Miljković J. The first 25 years of Acta Dermatovenerologica Alpina, Pannonica et Adriatica. Acta Dermatovenerol Alp Pannonica Adriat. 2016;25:63.

14. Poljak M. Coverage of Acta Dermatovenerologica Alpina, Pannonica et Adriatica in Elsevier's CiteScore index: a new tool for measuring the citation impact of academic journals. Acta Dermatovenerol Alp Pannonica Adriat. 2017;26:1-2.

15. Šterbenc A, Oštrbenk A. Elsevier's CiteScore index values for Acta Dermatovenerologica Alpina, Pannonica et Adriatica: a 2016 update. Acta Dermatovenerol Alp Pannonica Adriat. 2017;26:53.

16. Kokol P, Završnik J, Blažun Vošner H. Bibliographic-based identification of hot future research topics: an opportunity for hospital librarianship. J Hosp Librariansh. 2018;18:315-22.

17. Kokol P. Trend analysis of journal metrics: a new academic library service? J Med Libr Assoc. 2017;105:240-2.

18. Ostrbenk A, Skamperle M, Poljak M. Citation analysis of Acta Dermatovenerologica Alpina, Pannonica et Adriatica: 1992-2011. Acta Dermatovenerol Alp Pannonica Adriat. 2012;21:47-9.

19. Oštrbenk A, Poljak M. Citation analysis of Acta Dermatovenerologica Alpina, Pannonica et Adriatica: 1992-2013. Acta Dermatovenerol Alp Pannonica Adriat. 2015;24:1-3.

20. Chen KY, Luesukprasert l, Chou ST. Hot topic extraction based on timeline analysis and multidimensional sentence modeling. IEEE Trans Knowl Data Eng. 2007: 8:1016-25.

21. Endenich C, Trapp R. Cooperation for publication? An analysis of co-authorship patterns in leading accounting journals. Eur Account Rev. 2016;25:613-33. 